IZA DP No. 3117

Risk, Delegation, and Project Scope

Andreas Roider

October 2007 


\title{
Risk, Delegation, and Project Scope
}

\author{
Andreas Roider \\ University of Bonn, \\ CEPR and IZA
}

\section{Discussion Paper No. 3117 \\ October 2007}

\author{
IZA \\ P.O. Box 7240 \\ 53072 Bonn \\ Germany \\ Phone: +49-228-3894-0 \\ Fax: +49-228-3894-180 \\ E-mail: iza@iza.org
}

\begin{abstract}
Any opinions expressed here are those of the author(s) and not those of the institute. Research disseminated by IZA may include views on policy, but the institute itself takes no institutional policy positions.

The Institute for the Study of Labor (IZA) in Bonn is a local and virtual international research center and a place of communication between science, politics and business. IZA is an independent nonprofit company supported by Deutsche Post World Net. The center is associated with the University of Bonn and offers a stimulating research environment through its research networks, research support, and visitors and doctoral programs. IZA engages in (i) original and internationally competitive research in all fields of labor economics, (ii) development of policy concepts, and (iii) dissemination of research results and concepts to the interested public.
\end{abstract}

IZA Discussion Papers often represent preliminary work and are circulated to encourage discussion. Citation of such a paper should account for its provisional character. A revised version may be available directly from the author. 


\section{ABSTRACT}

\section{Risk, Delegation, and Project Scope}

This paper studies a partial-contracting model where an agent may provide effort to increase a project's scope before some later decisions have to be taken. Consistent with existing empirical evidence, we find a positive relationship between exogenous risk and delegation. That is, we show that only if exogenous risk is sufficiently large, the risk-neutral principal may prefer to delegate authority over decisions to the risk-averse agent. Intuitively, for incentive reasons, the principal may optimally want to allow the agent to reduce his risk exposure. Nevertheless, even endogenous risk may be higher when the risk-averse agent has control.

JEL Classification: D86, D21, D23, G34, L14

Keywords: delegation, authority, risk, partial contracting

Corresponding author:

Andreas Roider

Wirtschaftspolitische Abteilung

University of Bonn

Adenauerallee 24-42

53113 Bonn

Germany

E-mail: roider@uni-bonn.de

\footnotetext{
* I would like to thank Anke Kessler, Christoph Lülfesmann, Gerd Muehlheusser, Stefan Reichelstein, Patrick Schmitz, Urs Schweizer, and seminar participants at the EEA meetings 2007 in Budapest, the International Industrial Organization Conference 2007 in Savannah, the Personnel Economics Workshop 2007 in Tübingen, and the SFB/TR15 conference 2006 in Frauenwörth for helpful discussions and comments. I would also like to thank the German Science Foundation for financial support through SFB/TR 15 "Governance and the Efficiency of Economic Systems" and through a research fellowship.
} 


\section{Introduction}

Motivation Authority over decision-making is frequently delegated to lower levels of a hierarchy. Indeed, Rajan and Wulf (2006) document that recently entire layers of hierarchies are eliminated (i.e., more and more managers report directly to the $\mathrm{CEO}$ ) and more managers are being appointed officers of the firm. This seems to hint at a trend towards more delegation of authority, ${ }^{1}$ and raises the question under which circumstances it is optimal for a principal to grant lower tiers the right to take relevant decisions.

Interestingly, there is evidence for a positive relationship between exogenous risk and delegation, i.e., there seems to be more delegation in settings that are more risky. At first sight, this observation might be surprising because it has frequently been argued that riskaverse managers might try to reduce total firm risk at the expense of the expected return, which might not be in the best interest of (well-diversified) shareholders. ${ }^{2}$ This line of reasoning would imply a negative relationship between risk and delegation; contrary to what has been found in the empirical literature. In particular, in a recent study on the retail banking sector Nagar (2002) finds that high-growth, volatile, and innovative retail banks delegate more authority to branch managers. In the franchising context, Lafontaine (1992) considers the decision of potential franchisors to either operate a given store directly (i.e., to keep it company-owned) or to franchise it, where a franchisee has considerably greater autonomy in terms of decision-making. Considering a variety of industries (such as fastfood restaurants, business aids and services, construction and maintenance, and nonfood retailing), Lafontaine (1992) finds that the higher is exogenous risk (measured by the average proportion of discontinued outlets), ${ }^{3}$ the more likely is a given store to be franchised (for a survey of related results, see Lafontaine and Bhattacharyya, 1995). Finally, Acemoglu, Aghion, Lelarge, Van Reenen, and Zilibotti (2007) study three large datasets of French and British manufacturing firms and find that firms facing greater uncertainty (i.e., firms that are closer to the technological frontier, firms in more heterogenous environments, and younger firms) are more likely to decentralize decision-making.

In the present paper, we propose one possible channel through which higher exogenous

\footnotetext{
${ }^{1}$ At the same time, this indicates that CEOs are getting directly connected deeper down in hierarchies.

${ }^{2}$ See Amihud and Lev (1981) and May (1995) for discussions of this issue and for empirical evidence in the context of conglomerate mergers. In the context of firms' financing decisions, Lewellen (2006) documents that managers' behavior is influenced by their desire to reduce the riskiness of their personal income streams.

${ }^{3}$ For a discussion of various empirical measures of risk, see Lafontaine (1992, p. 271ff.).
} 
risk might make delegation more desirable. As discussed above, delegation of authority may allow agents to reduce their risk exposure. We argue that such risk reduction may indeed be beneficial from a principal's perspective if large risk stifles agents' initiative, i.e., higher risk may lead to more delegation for incentive reasons.

An illustrative example: the Hudson's Bay Company case To illustrate what we have in mind, in the following we briefly discuss a historic example that has frequently been employed to highlight the relevance of organizational design for firm performance: the Hudson's Bay Company case (see e.g., Milgrom and Roberts, 1992, Roberts, 2004, and the references cited therein). In 1670, Hudson's Bay Company (henceforth, HBC) was granted a royal monopoly by King Charles II of England for trade with all lands draining into the Hudson Bay. Having approximately fifteen times the size of the UK, at that time Hudson Bay was a trackless wilderness sparsely populated by some aboriginal people, but rich in animal fur, which was in high demand in Europe. Fur trade was HBC's main business. HBC had set up half a dozen forts on the shores of Hudson Bay waiting for customers seeking Europeanmade goods in exchange for their furs. In the course, it amassed huge profits. Then, in 1779 the North West Company of Montreal (henceforth, NWC) entered the market. Initially, this did not seem to be a threat because NWC faced a huge cost disadvantage. Due to HBC's royal monopoly, NWC could not ship goods through Hudson Bay. Instead, it was forced to first transport goods and furs over land to Montreal; resulting in costs twice as high as HBC's. Nevertheless, by 1809 NWC had an $80 \%$ market share and was immensely profitable, while HBC was near bankruptcy. How did this come about? To this end, it is important to note that, while being in the same business, HBC's and NWC's organizational designs differed markedly. In the case of HBC, decision-making (for example, on prices and on how business was to be conducted) was centralized in headquarters in London. ${ }^{4}$ Moreover, given the geography and climate of Hudson Bay, there was only very limited possibility for communication between local employees and London: ships were able to bring in goods (and new instructions) from Europe only once a year. This lack of flexibility to conduct business as they saw fit stifled the local employees' initiative to trade with people far from the bay: given the wilderness and the uncertainties of demand and supply, such trade involved huge risks. In contrast to HBC's approach, NWC had erected dozens of trading posts inland

\footnotetext{
${ }^{4}$ This form of governance was meant to counter the perceived danger of its (far away) employees frittering away or misappropriating profits.
} 
right where the furs where collected. In addition, decision-making was delegated to local "Nor'Westers"; thereby giving them the opportunity to better adjust to the perceived risks and giving them an incentive to actually go to the remote areas. Initially, HBC was slow to react to NWC's challenge, but eventually it simply copied NWC's organizational design and - given its cost advantage - by 1820 had absorbed NWC through a merger.

As the Hudson's Bay Company case illustrates, agents might be reluctant to increase the scope of operations if they anticipate that through later (operative) decisions a principal exposes them to a lot of risk. Frequently, it will be difficult for a principal to commit to a certain (less risky) course of action beforehand. Hence, delegating authority to the agent (thereby allowing him to proceed as he sees fit) may provide the principal with a credible way of reducing the agent's risk exposure (and, as a consequence, may raise the agent's initiative). Such considerations will be the more important, the higher is exogenous risk in the first place, and hence through this channel higher exogenous risk may make delegation more desirable from a principal's perspective.

Model and results In our partial-contracting model, a risk-neutral principal (she) hires a risk-averse agent (he) to conduct some project. Only the agent is able provide a noncontractible effort that raises the scope of the project. Subsequent decisions are taken under uncertainty and may be made by either the principal or the agent (in case the principal decides to delegate authority). In line with the literature on partial contracting (see e.g., Aghion, Dewatripont, and Rey, 2002), we assume that only control over the decisions (but not the decisions themselves) are contractible. Finally, uncertainty regarding the state of the world is resolved, and the payoffs of the parties are realized. As we are mainly interested in the effect of risk on the desirability of delegation, we assume that the principal and the agent only differ in their risk attitudes, and we abstract from other potential conflicts of interest between the parties.

We obtain the following results. First, in line with the empirical evidence, we find that, for sufficiently low levels of exogenous risk, the risk-neutral principal prefers to retain control over decisions. However, for sufficiently large levels of exogenous risk, it is strictly optimal for the principal to delegate authority to the risk-averse agent, if there is a sufficiently pronounced risk-return trade-off. That is, there is a positive relationship between exogenous risk and delegation. Second, more generally, this result illustrates that, for incentive reasons, even a risk-neutral principal may find it optimal to allow an agent to reduce his risk exposure. 
Third, in the model the equilibrium project risk (measured by the variance of the project return) is endogenous and depends on the effort and decisions taken. Interestingly, it is possible that endogenous risk is higher when authority over decisions is delegated to the risk-averse agent, i.e., there might even be a positive relationship between endogenous risk and delegation. In general, however, the relationship between endogenous risk and delegation is ambiguous.

The remainder of the paper proceeds as follows. In Section 2, we discuss the related literature. The model is introduced in Section 3, and Section 4 contains our results. Section 5 concludes. All proofs are relegated to an appendix in Section 6.

\section{Related Literature}

The present paper contributes to four strands of the literature.

First, in terms of the structure of the model, our paper builds on the emerging partialcontracting approach to delegation, ${ }^{5}$ which considers settings where only control over decisions, but not the decisions themselves, are contractible or at least transferable (see e.g., Aghion, Dewatripont, and Rey, 2002, 2004). However, the partial-contracting literature has not studied the role of risk and risk attitudes on optimal assignments of authority. By incorporating ideas from the literature on project selection (see e.g., Hirshleifer and Suh, 1992; Demski and Dye, 1999; Core and Qian, 2002), we make a step in filling this gap. As the present paper, the literature on project selection extends the standard moral-hazard framework by allowing for the possibility that after effort provision some decisions have to be made. However, this literature does not consider delegation, but assumes that the agent has authority. 6

Second, in terms of the underlying idea, the present paper is related to a strand of the literature that explains delegation through its function as a commitment device. That is, through delegation of authority to an agent (who behaves differently) a principal might be able to reduce time-consistency problems (where she prefers some behavior ex-ante, to which she, however, cannot commit ex-post). On the one hand, such delegation might be advantageous in strategic interactions with third parties (see e.g., Rogoff, 1985; Vickers, 1985; Sappington, 1986; Fershtman and Judd, 1987; Melumad and Mookherjee, 1989). On

\footnotetext{
${ }^{5}$ For recent surveys of the literature on delegation, see e.g., Mookherjee (2006) and Poitevin (2000).

${ }^{6}$ For an exception, see Dutta and Reichelstein (2002), which, however, differs in other important aspects from the present paper.
} 
the other hand, similar to the present paper, delegation might be optimal because it convinces the agent that the principal will not interfere ex-post; thereby raising the agent's incentives ex-ante (see e.g., Aghion and Tirole, 1997; Burkart, Gromb, and Panunzi, 1997). While Aghion and Tirole's (1997) paper on real and formal authority considers a similar sequence of events, ${ }^{7}$ it differs from the present paper in the interpretation of the effort of the agent. While in Aghion and Tirole (1997) the agent expends effort to acquire information about the prospects of various courses of action, in our paper the agent's effort increases the scope of the project, i.e., its size. Moreover, Aghion and Tirole (1997) do not study the relationship between risk and delegation.

Third, our paper is related to earlier work investigating how a positive relationship between exogenous risk and delegation might arise (see e.g., Prendergast, 2002; Acemoglu, Aghion, Lelarge, Van Reenen, and Zilibotti, 2007). Prendergast's (2002) main aim is to explain the positive relationship between risk and pay for performance incentives that, in contrast to what is predicted by standard principal-agent theory, is frequently observed in empirical studies. ${ }^{8}$ In Prendergast (2002) an agent has to specialize in one out of many tasks and subsequently chooses a variable effort. In contrast to the present paper, the agent is assumed to be risk-neutral, the agent has private information about the riskiness of output, and costly input and output monitoring by the principal are feasible. Prendergast (2002) shows that the principal prefers to retain control over task choice if risk is low (i.e., if the correct task is rather obvious). In this case, through input monitoring, the principal will ensure that the agent focuses on the desired task. On the other hand, if risk is high (i.e., if it is unclear to the principal what the right task is), it is optimal for the principal to delegate task choice to the better informed agent and to motivate him through pay-for-performance. ${ }^{9}$ In Acemoglu, Aghion, Lelarge, Van Reenen, and Zilibotti (2007), the agent has superior information with respect to the correct course of action. The principal has access to publicly available information only and prefers to retain control if publicly available information

\footnotetext{
${ }^{7}$ See also Dewatripont and Tirole (1994), Legros and Newman (2004), and Hart and Moore (2005).

${ }^{8}$ For other recent explanations of a positive risk-incentive trade-off, see e.g., Core and Qian (2002), Baker and Jorgensen (2003), Raith (2003), and Guo and Ou-Yang (2006).

${ }^{9}$ See also Bester (2003) who does not focus on the role of risk (which is taken to be exogenous), but, more generally, on the role of externalities caused by certain allocations of authority (see also Bester, 2005). In particular, Bester (2003) assumes that larger projects impose higher (exogenously given) costs on the agent. In the present paper, such costs arise through a risk-return trade-off involved in decision-making. Under special circumstances a positive relationship between exogenous risk and delegation may emerge in Bester's (2003) model. In contrast to the present paper, Bester (2003) assumes that decisions are made before effort is exerted.
} 
is sufficiently precise. If publicly available information is relatively imprecise, the principal prefers to delegate authority to the agent. Hence, in both Prendergast (2002) and Acemoglu, Aghion, Lelarge, Van Reenen, and Zilibotti (2007) private information of the agent plays an important role.

Finally, our paper adds to a strand of the literature that explores why risk reduction by an agent might be beneficial even from a risk-neutral principal's perspective. ${ }^{10}$

\section{The Model}

A risk-neutral principal $P$ and a risk-averse agent $A$ conduct some project. Figure 1 illustrates the sequence of events. At date 0 the principal offers the agent a contract. Feasible contracts are discussed in more detail below.

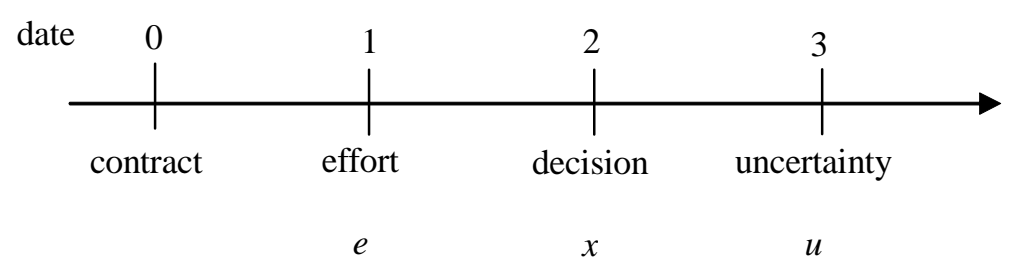

Figure 1: Sequence of events

At date 1, the agent (and only the agent) may provide some unobservable effort $e \geq 0$, where the disutility of effort is given by $\frac{1}{2} e^{2}$. The agent's effort raises the scope of the project (i.e., the larger is $e$, the larger is the size of the project). At date 2 , a decision $x \in[0,1]$ has to be taken (by the principal or by the agent depending on who has authority). We assume that $x$ directly fixes the expected return per unit of the project, i.e., the expected return of the project is given by $e \cdot x$. For example, in the context of retail banking discussed in the introduction, $e$ might represent the number of new credit customers a branch manager approaches (for analytical convenience, we assume that $e$ is continuous). In this case, the expected return per customer might depend on whether an aggressive or a conservative credit policy $x$ is pursued. Alternatively, in the context of manufacturing, $e$ might represent some

\footnotetext{
${ }^{10} \mathrm{At}$ a basic level, this might be the case because risk-averse agents need to be compensated for the risk they bear (see e.g., Smith and Stulz, 1985). In contrast, in our model risk reduction may increase the agent's initiative. For an alternative explanation see DeMarzo and Duffie (1995) who consider a model where an agent may engage in financial hedging, which results in profits that are more informative of project quality; thereby allowing better termination decisions by the principal.
} 
production quantity, and $x$ might be determined by the subsequent marketing strategy. ${ }^{11}$ While $x$ determines the expected return, the true return $u$ per unit of the project is only realized at date 3 . In the following, we want to allow for the possibility that there is a risk-return trade-off in decision-making, i.e., a more ambitious course of action (i.e., a higher $x)$ might not only yield a higher expected return, but might also come with higher risk (i.e., it might lead to a higher variance of the project return). Frequently, it will be the case that a more ambitious goal involves greater risks, while the return to a more modest course of action might (almost) be predetermined. ${ }^{12}$ Consequently, we assume that $u$ is a normally distributed random variable with expected value $x$ and variance $r \cdot x^{\gamma}$, where $r>0$ and $\gamma \geq 0$ are parameters. Our measure of exogenous risk is given by $r$, i.e., a larger $r$ will be interpreted as higher exogenous risk. For $\gamma=0$, the variance of the project return is independent of $x$. For $\gamma>0$, there is a positive risk-return trade-off, i.e., the variance of the project return is increasing in $x$.

Payoffs of the parties We now turn to the payoffs of the parties. As discussed above, the main concern of the paper is how the underlying riskiness of projects might influence the decision of the principal to delegate authority to the agent. In order to isolate this effect, we abstract from other potential conflicts of interest between the principal and the agent with respect to the decision, and assume that the parties only differ in their risk preferences. Formally, we assume that both the principal and the agent derive a (gross) payoff of $e \cdot u$ from conducting the project. These payoffs might, for example, represent private benefits that each of the parties derives from conducting the project (e.g., due to changes in reputation or career prospects). Alternatively, one could assume that the project generates a total gross return of two times $e \cdot u$, which the parties share equally. Note that in this case the results of the paper do not depend on the assumption of equal sharing, but would continue to hold for any linear incentive contract. ${ }^{13}$ Consequently, as $P$ is risk-neutral, her expected payoff

\footnotetext{
${ }^{11}$ The multiplicative form of payoffs implies that $A$ 's incentives to exert effort depend on which decisions are taken later on. It will become clear below that if $A$ 's return to effort were independent of $x$, the principal would never find it optimal to delegate authority to the agent. Papers considering a similar payoff structure include Guo and Ou-Yang (2006), Baker and Jorgensen (2003), and Sung (1995).

${ }^{12}$ For example, the literature on project selection discussed in Section 2 typically assumes a positive riskreturn trade-off.

${ }^{13}$ In this respect, it is interesting to note various empirical findings on how franchisors adjust their contract terms to differences in risk. First, Lafontaine (1992) documents that franchisors respond to differences in risk by relying on franchising to varying degrees (rather than by modifying incentive provisions, such as the royalty rate). Second, she finds that both the franchise fee and the royalty rate do not seem to vary across potential franchisees, and Lafontaine and Shaw (1999) show that both are very persistent over time. In their
} 
from the project is given by

$$
\pi(e, x) \equiv E[e \cdot u]=e \cdot x .
$$

On the other hand, the risk-averse agent evaluates his payoff with a concave utility function, and, for tractability, we assume that he has an exponential utility function with constant absolute risk aversion $\rho>0$. This allows to represent $A$ 's expected utility by its certainty equivalent, ${ }^{14}$ which (net of effort costs) is given by

$$
a(e, x) \equiv e \cdot x-\frac{1}{2} \cdot \rho \cdot e^{2} \cdot x^{\gamma} \cdot r-\frac{1}{2} e^{2} .
$$

While the agent's utility is increasing in the expected value of the project return, it is decreasing in its variance. Moreover, the agent has to bear the effort costs. The reservation utility of $A$ is assumed to be zero.

Information and contracts In line with the literature on partial contracting we assume that only control over the decision, but not the decision itself is contractible. Hence, at date 0 the principal (who is assumed to initially have control) may decide to delegate authority over the decision to the agent. That is, initial contracts take the form $[j, t]$, where $j \in\{A, P\}$ denotes which of the parties has authority and where $t$ denotes an unconditional transfer payment from $A$ to $P$.

\section{Analysis of the Model}

When deciding about whether to delegate authority to the agent, the principal aims to maximize her expected payoff subject to the agent's participation constraint. Intuitively, because the principal cannot commit not to behave opportunistically at the decision stage (i.e., she cannot commit not to select the most profitable, but also most risky, course of action), she faces the following trade-off. ${ }^{15}$ On the one hand, if the principal has authority (P-control), she will select a large $x$ promising her a high expected return. However, in this case the risk-averse agent anticipates that his payoff will be relatively risky, and hence his

sample, $58 \%$ of firms never changed their royalty rate. Hence, at least in the franchising context, delegation seem to be the primary way to adjust to differences in risk (rather than adjustment of incentive contracts). Also, in his study on the banking sector, Nagar (2002) reports that the extent of incentive compensation plays no significant role in explaining the extent of delegation (and that incentive pay only comprises seven to ten percent of branch managers' total pay).

${ }^{14}$ See e.g., Laffont and Martimort (2002, p. 379ff.).

${ }^{15}$ This immediately follows from the fact that the decision itself is not contractible. 
incentive to increase the scope of the project will be relatively low. On the other hand, if the agent is granted authority (A-control), he may find it optimal to make a decision that, while promising only a moderate return, at the same time exposes him to less risk. As a consequence, while under $A$-control the agent may distort the decision (relative to the decision preferred by the principal), this will leave him with higher effort incentives than P-control.

In particular, in the following we show that for large enough levels of exogenous risk $r$, the principal may find it optimal to delegate authority to the risk-averse agent. To do so, we consider $P$-control and $A$-control in turn. In a first step, we derive the equilibrium decisions $x^{j}(e)$ and effort choices $e^{j}$ given $j$-control, where $j=P, A$. In a second step, this allows to determine the optimal transfer payments $t^{j}$ that the principal sets such that the agent's participation constraint is binding. That is, given $j$-control, we have $t^{j}=a\left(e^{j}, x^{j}\left(e^{j}\right)\right)$ for $j=P, A$, where $t^{j} \geq 0$ because $A$ always has the option to choose $e=0$. Finally, we compare the principal's payoff under each of the two regimes.

$\boldsymbol{P}$-control For the moment, assume that $P$ retains authority over the decision. In this case, it follows from (1) that at date 2 the principal chooses $x^{P}(e)=1$ for all $e>0$. Anticipating that the principal will aim for the most risky project, it follows from (2) that the agent selects his effort level such that

$$
e^{P}=\arg \max _{e}\{a(e, 1)\}=\frac{1}{1+\rho r}
$$

where the effort level $e^{P}$ is decreasing in both exogenous risk $r$ and the risk-aversion parameter $\rho$. These results are summarized in the following lemma.

Lemma 1 (equilibrium outcome under P-control) Suppose the principal has authority. In this case, she takes the decision that promises the highest expected return (i.e., $\left.x^{P}\left(e^{P}\right)=1\right)$, and the agent selects an effort level given by $e^{P}=\frac{1}{1+\rho r}$.

$\boldsymbol{A}$-control Now suppose that the principal delegates authority to the agent. This implies that at date 2 the risk-averse agent takes a decision $x^{A}(e)$ that maximizes his expected utility, and hence he may deviate from the course of action preferred by the principal. In particular,

$$
x^{A}(e) \in \arg \max _{x}\{a(e, x)\}
$$


where (2) implies ${ }^{16}$

$$
a_{x}(e, x)=e-\frac{1}{2} \cdot \rho \cdot e^{2} \cdot \gamma \cdot x^{\gamma-1} \cdot r .
$$

Hence, selecting a larger $x$ has two effects. First, it raises the expected return of the project. At the same time, it leads to a higher variance, which reduces the agent's utility. This negative variance effect is the larger, the larger is the scope of the project (i.e., the larger is $e)$. Intuitively, the larger the project is, the more the agent will be inclined to insure himself by choosing a less risky course of action. Consequently, there exists a threshold level $\widehat{e}$ : for effort levels below this threshold the implied risk is sufficiently small, such that (just as the principal) the agent chooses $x=1$. However, for levels of $e$ above this threshold, $A$ finds it optimal to distort $x$ downwards in order to reduce his risk-exposure. This discussion is summarized in the following lemma.

Lemma 2 (decision under A-control) Suppose the agent has authority. For sufficiently low levels of effort, the agent makes the same decision as the principal. However, given sufficiently large effort levels, the agent prefers to downward distort the decision. Formally, for $e>\widehat{e}$ we have $x^{A}(e)<1$, and $x^{A}(e)=1$ otherwise, where $\widehat{e} \equiv \frac{2}{\rho r} \cdot \min \left\{\frac{1}{\gamma}, 1\right\}$.

Proof. See the Appendix.

Let us now turn to the agent's effort choice at date 1, which solves

$$
e^{A} \in \arg \max _{e}\left\{a\left(e, x^{A}(e)\right)\right\} .
$$

Lemma 2 raises the question under which circumstances the agent indeed finds it optimal to choose an effort level sufficiently large to imply a subsequent downward distortion of the decision. Only in this case $A$-control and $P$-control will lead to different equilibrium outcomes. First, if the risk-return trade-off is relatively weak (i.e., if $\gamma$ is relatively low), $A$-control will lead to the same equilibrium outcome as $P$-control. Second, suppose that the risk-return trade-off is sufficiently pronounced (i.e., assume that $\gamma$ is sufficiently large). If the level of exogenous risk $r$ is relatively low, the threshold value $\widehat{e}$ is relatively large. That is, even if the project scope is relatively large, the agent would still be willing to take the most ambitious decision $x=1$. Put differently, an even larger project scope would be required to make a downward distortion of the decision desirable for the agent (see Lemma 2). As effort costs are convex, choosing such a high $e$ will not be optimal, and as a consequence $A$-control

\footnotetext{
${ }^{16}$ Throughout, subscripts denote partial derivatives.
} 
will again lead to the same equilibrium outcome as $P$-control. If, however, exogenous risk $r$ is relatively large, $\widehat{e}$ is small, and the agent finds an effort level above $\widehat{e}$ profitable. In this case, $A$-control leads to a different outcome than $P$-control: relative to $P$-control, the agent chooses a higher effort level, but picks a decision that implies less risk later on.

Lemma 3 (equilibrium outcome under A-control) Suppose the agent has authority. If the risk-return trade-off is sufficiently pronounced and exogenous risk is sufficiently large, then, compared to P-control, equilibrium effort is larger, but the equilibrium decision is smaller. Formally, (i) if $\gamma>2$ and $r>\widehat{r} \equiv \frac{2}{\rho(\gamma-2)}$, then $e^{A}=\left(\frac{\gamma-2}{\gamma}\right)\left(\frac{\widehat{e} \gamma}{\gamma-2}\right)^{\frac{1}{\gamma}}>e^{P}$ and $x^{A}\left(e^{A}\right)=\sqrt[\gamma-1]{\frac{\widehat{e}}{e^{A}}}<1$, and (ii) $e^{A}=e^{P}$ and $x^{A}\left(e^{A}\right)=1$ otherwise.

Proof. See the Appendix.

Hence, Lemma 3 implies that if $\gamma>2$ and $r>\widehat{r}$ hold, the equilibrium decisions and effort levels under $P$-control and $A$-control differ. That is, only in such cases there is an ex-post conflict of interest between $P$ and $A$.

Optimal allocation of control Having derived the equilibrium effort levels and decisions under both $P$-control and $A$-control, we now investigate under which circumstances the principal finds it optimal to delegate authority to the risk-averse agent. ${ }^{17} P$ delegates authority to $A$ whenever she obtains a higher total payoff from doing so, i.e., if and only if

$$
\pi\left(e^{A}, x^{A}\left(e^{A}\right)\right)+t^{A}>\pi\left(e^{P}, x^{P}\left(e^{P}\right)\right)+t^{P}
$$

which can only be the case if there is an ex-post conflict of interest between the parties. Indeed, in the following we show that whenever there is such a conflict, the principal prefers to delegate authority to the agent. To see this, first note that in this case we have $t^{A}=$ $a\left(e^{A}, x^{A}\left(e^{A}\right)\right)>a\left(e^{P}, x^{P}\left(e^{P}\right)\right)=t^{P}$ because under $A$-control the agent chooses both $e$ and $x$, and hence under this regime his equilibrium utility (gross of the transfer payment) is higher than under $P$-control. Second, it turns out that, despite the fact that under $A$-control a smaller $x$ is selected, the increase in effort is sufficiently large such that also the expected return of the project goes up. That is, $\pi\left(e^{A}, x^{A}\left(e^{A}\right)\right)>\pi\left(e^{P}, x^{P}\left(e^{P}\right)\right)$ holds.

\footnotetext{
${ }^{17}$ We assume that if the principal is indifferent, she retains control. For example, assume that she derives some (arbitrarily small) private benefit of control that is independent of both $e$ and $x$.
} 
Proposition 1 (optimal allocation of control) If the risk-return trade-off is sufficiently pronounced, then, for sufficiently high levels of exogenous risk, the risk-neutral principal finds it strictly optimal to delegate authority to the risk-averse agent. Otherwise, the principal retains control. Formally, A-control is strictly optimal if both $\gamma>2$ and $r>\widehat{r}$ hold.

Proof. See the Appendix.

Hence, in accordance with the empirical evidence we find a positive relationship between exogenous risk and delegation. Finally, note that the threshold value $\widehat{r}$ for the level of exogenous risk beyond which $A$-control is optimal is a decreasing function of both the agent's degree of risk aversion $\rho$ and the degree $\gamma$ of the risk-return trade-off.

Equilibrium project risk In equilibrium the agent responds to exogenous risk through a certain choice of effort level and decision. Consequently, the equilibrium riskiness of the project (i.e., the equilibrium variance of the project return) is endogenous. In the following, we study how the equilibrium variance of the project return varies with exogenous risk (and hence, with the incidence of delegation). The equilibrium variance is given by

$$
V^{*} \equiv \operatorname{Var}\left(e^{j} \cdot u\right)=\left(e^{j}\right)^{2} \cdot x^{j}\left(e^{j}\right)^{\gamma} \cdot r,
$$

where $j=A$ if $\gamma>2$ and $r>\widehat{r}$, and $j=P$ otherwise. It turns out that there is a hump-shaped relationship between exogenous risk $r$ and the equilibrium variance $V^{*}$. First, consider the case that $P$-control is optimal, where Lemma 1 and (8) imply that $V^{*}=\left(e^{P}\right)^{2} \cdot r$. Hence, on the one hand, an increase in $r$ has a direct positive effect on $V^{*}$. On the other hand, indirectly, larger values of $r$ lead the agent to reduce his effort level (see again Lemma 1), which reduces the equilibrium variance of the project return. As will be shown below, for low levels of $r$ the former effect dominates, and endogenous risk is increasing in $r$. However, for sufficiently high values of $r$ the reduction in the effort level is sufficient to lead to a negative relationship between $r$ and endogenous risk.

Second, consider the case that $A$-control is optimal; implying that $V^{*}=\left(e^{A}\right)^{2} \cdot x^{A}\left(e^{A}\right)^{\gamma} \cdot r$. Here, the equilibrium variance can be shown to be a decreasing function of the level of exogenous risk. To see this, note that the agent's equilibrium choice of $x$ is decreasing in the level of exogenous risk. In particular, in equilibrium, the agent reacts to larger levels of $r$ by reducing $x$ such that $x^{A}\left(e^{A}\right)^{\gamma} \cdot r$ remains constant. This observation in combination with the fact that the equilibrium effort level is decreasing in $r$ (see Lemma 2 and 3) implies the 
result. The above discussion is summarized in Proposition 2 and illustrated in Figure 2 (for the case $\gamma>2$ ).

Proposition 2 (equilibrium variance of the project return) The equilibrium variance of the project return is a hump-shaped function of exogenous risk, and hence the relationship between endogenous risk under $P$-control and A-control is ambiguous. Formally, $V^{*}$ is a continuous function of $r$, and $(i)$ if $\gamma \leq 2$, we have $V_{r}^{*}>(<) 0$ for all $r<(>) \frac{1}{\rho}$, and (ii) if $\gamma>2$ (and hence A-control is possibly optimal), we have $V_{r}^{*}>(<) 0$ for all $r<(>) \min \left\{\frac{1}{\rho}, \widehat{r}\right\}$, where $\frac{1}{\rho} \leq \widehat{r}$ if and only if $\gamma \leq 4$.

Proof. See the Appendix.

Interestingly, while Proposition 1 implies that in situations with larger exogenous risk it is more likely that authority is delegated to the risk-averse agent, Proposition 2 shows that an analogous positive relationship might exist with respect to endogenous risk and the incidence of delegation. It might very well be the case that the observed variance of the project return is larger in cases where $A$ has authority than in cases where the risk-neutral principal retains control. Such a case is illustrated by points $y$ and $z$ in Figure 2 .

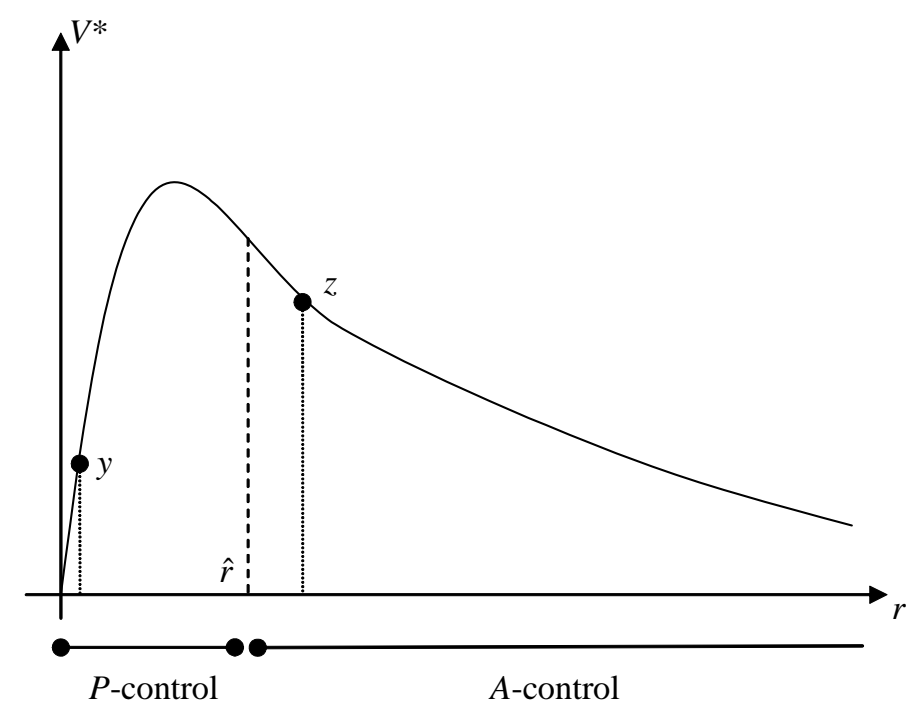

Figure 2: Equilibrium variance of the project return for the case $\gamma>2$

Finally, sofar we have assumed that the agent has sufficient wealth to be able to make any required payments. Now assume that the agent possesses some limited wealth $w \geq 0$ only. 
As long as the agent's payoff $e \cdot u$ from the project constitutes a non-monetary private benefit, the discussion above immediately implies that Propositions 1 and 2 continue to hold. To see this, note that with limited wealth the optimal transfer payment under $j$-control is given by $t^{j}=\min \left\{a\left(e^{j}, x^{j}\left(e^{j}\right)\right), w\right\}$ for $j=P, A$. Hence, whenever there is an ex-post conflict of interest between $P$ and $A$, we still have $t^{A} \geq t^{P}$. Moreover, as shown in the proof of Proposition 1, whenever $A$-control is strictly optimal we have $\pi\left(e^{A}, x^{A}\left(e^{A}\right)>\pi\left(e^{P}, x^{P}\left(e^{P}\right)\right)\right.$, which, in combination with (7), implies the claim. ${ }^{18}$

\section{Conclusion}

Various empirical studies provide evidence for a positive relationship between exogenous risk and delegation of authority to lower levels of a hierarchy. Motivated by these (perhaps surprising) findings, we identify a channel through which more risk might lead to more delegation. We consider a partial-contracting model, where a risk-averse agent may exert effort to increase the scope of a project. Subsequent decisions may in principle be made either by the risk-neutral principal or by the agent. As only control over the decisions, but not the decisions themselves are contractible, the principal cannot commit to a certain course of action ex-ante. Decisions may involve a risk-return trade-off. That is, decisions promising a higher expected return may imply more risk. Hence, from a theoretical point of view, we combine elements of the recent literature on partial-contracting and the literature on project selection, where a risk-neutral principal and a risk-averse agent interact.

The risk-neutral principal faces the following trade-off. On the one hand, if she keeps authority, she selects the project yielding the highest expected return. However, thereby, she exposes the agent to a lot of risk, and this may reduce the agent's initiative. On the other hand, if she delegates authority to the agent, the agent will proceed more cautiously at the decision stage. At the same time, as the agent anticipates that the project return will be less risky, he has higher incentives to increase the project's scope; making delegation potentially profitable for the principal. Hence, delegation might be optimal not despite, but exactly because the agent is risk-averse. The paper has three main results. First, in accordance with the empirical evidence, the principal finds it strictly optimal to delegate authority to the risk-averse agent if and only if exogenous risk is sufficiently large (and the risk-return trade-

\footnotetext{
${ }^{18}$ The relationship between limited wealth and delegation is the main focus of recent papers by Aghion and Rey (2003), Bester and Krähmer (2006), and Puschke (2007).
} 
off is not too small). Second, this shows that, for incentive reasons, even for a risk-neutral principal it might be optimal to allow an agent to reduce total firm risk. Finally, contrary to what one might have expected, the relationship between endogenous risk and delegation is ambiguous. Hence, it is possible that endogenous risk is larger when the risk-averse agent has control. However, in general, the relationship between endogenous risk and delegation depends on the underlying distribution of exogenous risk.

\section{Appendix}

\subsection{Proof of Lemma 2}

Inspecting (5) reveals that $a(e, x)$ is strictly concave in $x$ if and only if $\gamma>1$. First, suppose,

$\gamma>1$. In this case, it immediately follows from (5) that $x^{A}(e)=\sqrt[\gamma-1]{\frac{2}{\gamma \rho r} \cdot \frac{1}{e}}<1$ if $e>\frac{2}{\gamma \rho r}$, and $x^{A}(e)=1$ if $e \leq \frac{2}{\gamma \rho r}$. Second, suppose $\gamma \leq 1$. In this case, we have $x^{A}(e) \in\{0,1\}$, and, given (2), we have $x^{A}(e)=1$ if $e-\frac{1}{2} \cdot \rho \cdot e^{2} \cdot r \geq 0$, which is the case if $e \leq \frac{2}{\rho r}$. Taken together, this implies the result.

\subsection{Proof of Lemma 3}

(a) In a first step, we prove that $e^{A}=e^{P}$ and $x^{A}\left(e^{A}\right)=x^{P}\left(e^{P}\right)=1$ if $\gamma \leq 2$. Define $a^{A}(e) \equiv a\left(e, x^{A}(e)\right)$. First, suppose $\gamma \leq 1$. Lemma 2 and (2) imply

$$
a^{A}(e)=\left\{\begin{array}{cl}
e-\frac{1}{2} \cdot \rho \cdot e^{2} \cdot r-\frac{1}{2} e^{2} & , \text { if } e \leq \frac{2}{\rho r} \\
-\frac{1}{2} e^{2} & , \text { if } e>\frac{2}{\rho r}
\end{array},\right.
$$

and hence $e>\frac{2}{\rho r}$ cannot be optimal because it is dominated by $e=0$. As a consequence, we have $e^{A}=e^{P}$ if $e^{P}=\frac{1}{1+\rho r} \leq \frac{2}{\rho r}=\widehat{e}$ holds, which is indeed the case. Second, suppose $1<\gamma \leq 2$. To prove the claim, we again show that in this parameter range some $e>\widehat{e}$ cannot be optimal. For all $e>\widehat{e}$, Lemma 2 and (2) imply

$$
\begin{aligned}
a^{A}(e) & =\left[e \cdot x^{A}(e)-\frac{1}{2} \cdot \rho \cdot e^{2} \cdot\left(x^{A}(e)\right)^{\gamma} \cdot r\right]-\frac{1}{2} e^{2} \\
& =e^{\left(\frac{2-\gamma}{1-\gamma}\right)} \cdot\left[\widehat{e}^{\left(\frac{1}{\gamma-1}\right)}-\frac{1}{2} \cdot \rho \cdot r \cdot \widehat{e}^{\left(\frac{\gamma}{\gamma-1}\right)}\right]-\frac{1}{2} e^{2} \\
& =e^{\left(\frac{2-\gamma}{1-\gamma}\right)} \cdot\left[\widehat{e}^{\left(\frac{1}{\gamma-1}\right)}-\frac{1}{\gamma} \cdot \widehat{e}^{\left(\frac{1}{\gamma-1}\right)}\right]-\frac{1}{2} e^{2} \\
& =\left(\frac{\gamma-1}{\gamma}\right) \cdot e^{\left(\frac{2-\gamma}{1-\gamma}\right)} \cdot \widehat{e}^{\left(\frac{1}{\gamma-1}\right)}-\frac{1}{2} e^{2},
\end{aligned}
$$


and hence

$$
a_{e}^{A}(e)=-\left(\frac{2-\gamma}{\gamma}\right) \cdot e^{\left(\frac{1}{1-\gamma}\right)} \cdot \widehat{e}^{\frac{1}{\gamma-1}}-e .
$$

Consequently, if $\gamma \leq 2$, we have $a_{e}^{A}(e)<0$ for all $e>\widehat{e}$, which implies $e^{A} \leq \widehat{e}$. Moreover, from Lemma 2 we know that $x^{A}(e)=1$ for all $e \leq \widehat{e}$. Hence, the agent chooses the effort level that maximizes $a(e, 1)$ subject to the constraint $e \leq \widehat{e}$, where $a(e, 1)$ is strictly concave in $e$. Consequently, similar to above we have $e^{A}=e^{P}$ if $e^{P}=\frac{1}{1+\rho r} \leq \frac{2}{\gamma \rho r}=\widehat{e}$ holds, which is indeed the case.

(b) In a second step, we consider the parameter range $\gamma>2$. To prove the result we show that it depends on the sign of $a_{e}(\widehat{e}, 1)=a_{e}^{A}(\widehat{e})=1-\widehat{e}(1+\rho r)$ whether $e^{A}$ lies above or below $\widehat{e}$. From (a) we know that $a(e, 1)$ is strictly concave in $e$. Moreover, (11) implies that

$$
a_{e e}^{A}(e)=-\underbrace{\left(\frac{2-\gamma}{\gamma}\right)}_{<0} \cdot \underbrace{\left(\frac{1}{1-\gamma}\right)}_{<0} \cdot e^{\left(\frac{\gamma}{1-\gamma}\right) \cdot \widehat{e}^{\frac{1}{\gamma-1}}}-1<0,
$$

and hence $e^{A}>\widehat{e}$ if and only if $a_{e}(\widehat{e}, 1)=1-\widehat{e}(1+\rho r)>0 \Longleftrightarrow 1-\frac{2}{\gamma \rho r} \cdot(1+\rho r)>0 \Longleftrightarrow$ $r>\frac{2}{\rho(\gamma-2)} \equiv \widehat{r}$. In this case, it follows from (11) that $e^{A}=\left(\frac{\gamma-2}{\gamma}\right)\left(\frac{\widehat{e} \gamma}{\gamma-2}\right)^{\frac{1}{\gamma}}$. If, however, $r \leq \frac{2}{\rho(\gamma-2)}$, by the same argument, we have $e^{A}=e^{P}$. It remains to show that $e^{A}>e^{P}$ holds in the relevant parameter range (i.e., where $\gamma>2$ and $r>\widehat{r}$ ). Note that $a_{e}(\widehat{e}, 1)>0$ implies $e^{A}, e^{P}>\widehat{e}$. Hence, as under both $P$-control and $A$-control the agent faces a concave problem, in order to prove the claim it suffices to show that $a_{e}^{A}(e)>a_{e}(e, 1)$ holds for all $e>\widehat{e}$. The Envelope-Theorem and (2) imply

$$
\begin{gathered}
a_{e}^{A}(e)>a_{e}(e, 1) \Longleftrightarrow x^{A}(e)-x^{A}(e)^{\gamma} \rho r e>1-\rho r e \\
\Longleftrightarrow \frac{1}{2} \rho r e \underbrace{\left[1-x^{A}(e)^{\gamma}\right]}_{>0}>\left[1-1^{\gamma} \frac{1}{2} \rho r e\right]-\left[x^{A}(e)-x^{A}(e)^{\gamma} \frac{1}{2} \rho r e\right]
\end{gathered}
$$

which is satisfied for all $e>\widehat{e}$ because Lemma 2 implies that the left-hand side is strictly positive, while (4) and (2) imply that the right-hand side is strictly negative.

\subsection{Proof of Proposition 1}

$A$-control can only be strictly optimal if it leads to a different equilibrium outcome than $P$ control, i.e., if both $\gamma>2$ and $r>\widehat{r}$ (see Lemma 3) hold, which we assume in the following. First, note that $t^{A}=a\left(e^{A}, x^{A}\left(e^{A}\right)\right)>a\left(e^{P}, x^{A}\left(e^{P}\right)\right) \geq a\left(e^{P}, 1\right)=t^{P}$. Second, we show 
that $\pi\left(e^{A}, x^{A}\left(e^{A}\right)\right)>\pi\left(e^{P}, x^{P}\left(e^{P}\right)\right)$ holds as well, which in combination with (7) implies the result. Lemma 1 implies $\pi\left(e^{P}, x^{P}\left(e^{P}\right)\right)=\frac{1}{1+z}$, where $z \equiv \rho r$. Moreover, Lemma 3 implies

$$
x^{A}(e)=\sqrt[\gamma-1]{\frac{\widehat{e}}{e}}=\left(\frac{2}{e \gamma z}\right)^{\frac{1}{\gamma-1}}=\left(\frac{2}{\gamma z}\right)^{\frac{1}{\gamma-1}} \cdot e^{-\left(\frac{1}{\gamma-1}\right)}
$$

and

$$
x^{A}\left(e^{A}\right) \cdot e^{A}=\left(\frac{2}{\gamma z}\right)^{\frac{1}{\gamma-1}} \cdot\left(e^{A}\right)^{\left(\frac{\gamma-2}{\gamma-1}\right)}=\left(\frac{1}{z}\right)^{\frac{2}{\gamma}} \cdot\left(\frac{2}{\gamma}\right)^{\frac{2}{\gamma}} \cdot\left(\frac{\gamma-2}{\gamma}\right)^{\left(\frac{\gamma-2}{\gamma}\right)} .
$$

Hence, we have

$$
\begin{aligned}
& \pi\left(e^{A}, x^{A}\left(e^{A}\right)\right)>\pi\left(e^{P}, x^{P}\left(e^{P}\right)\right) \Longleftrightarrow x^{A}\left(e^{A}\right) \cdot e^{A}>x^{P}\left(e^{P}\right) \cdot e^{P} \\
\Longleftrightarrow & \left(\frac{1}{z}\right)^{\frac{2}{\gamma}} \cdot\left(\frac{2}{\gamma}\right)^{\frac{2}{\gamma}} \cdot\left(\frac{\gamma-2}{\gamma}\right)^{\left(\frac{\gamma-2}{\gamma}\right)}>\frac{1}{1+z} \\
\Longleftrightarrow & {[z^{\left.-\frac{2}{\gamma}+z^{\frac{\gamma-2}{\gamma}}\right]} \cdot \underbrace{\left[\left(\frac{2}{\gamma}\right)^{\frac{2}{\gamma}} \cdot\left(\frac{\gamma-2}{\gamma}\right)^{\left(\frac{\gamma-2}{\gamma}\right)}\right]}_{>0}>1 .}
\end{aligned}
$$

Define $f(z)=z^{-\frac{2}{\gamma}}+z^{\frac{\gamma-2}{\gamma}}$. Note that at the boundary of the parameter range under consideration (i.e., at $r=\frac{2}{\rho(\gamma-2)} \Longleftrightarrow z=\frac{2}{\gamma-2}$ ), Lemma 3 implies that the left-hand side of the above inequality is equal to 1 . Hence, the above inequality is satisfied for all $z>\frac{2}{\gamma-2}$ if $f_{z}(z)>0$ for all $z>\frac{2}{\gamma-2}$ :

$$
\begin{aligned}
& f_{z}(z)>0 \Longleftrightarrow-\frac{2}{\gamma} \cdot z^{-\frac{2}{\gamma}-1}+\left(\frac{\gamma-2}{\gamma}\right) \cdot z^{\left(\frac{\gamma-2}{\gamma}\right)-1}>0 \\
\Longleftrightarrow & -\frac{2}{\gamma} \cdot z^{-1}+\left(\frac{\gamma-2}{\gamma}\right)>0 \Longleftrightarrow z>\frac{2}{\gamma-2},
\end{aligned}
$$

which concludes the proof.

\subsection{Proof of Proposition 2}

First, consider the case that $P$-control is optimal. Lemma 1 and (8) imply

$$
V^{*}=\frac{1}{(1+\rho r)^{2}} \cdot r
$$

and

$$
V_{r}^{*}=\frac{1}{(1+\rho r)^{2}}-\frac{2 \rho r}{(1+\rho r)^{3}}=\left(\frac{1}{1+\rho r}\right)^{2} \cdot\left(1-\frac{2 \rho r}{1+\rho r}\right)=\left(\frac{1}{1+\rho r}\right)^{2} \cdot\left(\frac{1-\rho r}{1+\rho r}\right)
$$


Hence, $V_{r}^{*}>0 \Leftrightarrow r<\frac{1}{\rho}$. Second, if $A$-control is optimal, it follows from Lemma 3 , Proposition 1, and (8) that

$$
V^{*}=\left(\frac{2}{\gamma \rho}\right)^{\frac{\gamma+2}{\gamma}} \cdot\left(\frac{\gamma-2}{\gamma}\right)^{\frac{\gamma-2}{\gamma}} \cdot r^{-\frac{2}{\gamma}},
$$

and hence in this case we have $V_{r}^{*}<0$ and $V_{r r}^{*}>0$. Finally, note that in the case $\gamma>2$ (where A-control is possibly optimal), we have $\left(e^{P}\right)^{2} \cdot x^{P}\left(e^{P}\right)^{\gamma} \cdot r=\left(e^{A}\right)^{2} \cdot x^{A}\left(e^{A}\right)^{\gamma} \cdot r$ if $r=\widehat{r}$, and $\frac{1}{\rho} \leq \widehat{r} \Leftrightarrow \frac{1}{\rho} \leq \frac{2}{\rho(\gamma-2)} \Leftrightarrow \gamma \leq 4$, which in combination with Lemma 3 concludes the proof.

\section{References}

Acemoglu, D., P. Aghion, C. Lelarge, J. Van Reenen, and F. Zilibotti (2007): "Technology, Information, and the Decentralization of the Firm," Quarterly Journal of Economics, forthcoming.

Aghion, P., M. Dewatripont, and P. Rey (2002): "On Partial Contracting," European Economic Review, 46(4-5), 745-753.

\section{$2(1), 115-138$.}

Aghion, P., And P. Rey (2003): “Allocating Decision Rights under Liquidity Constraints," in The Economics of Contracts, ed. by E. Brousseau, and J.-M. Glachant, pp. 193-212. Cambridge University Press, Cambridge.

Aghion, P., And J. Tirole (1997): "Formal and Real Authority in Organizations," Journal of Political Economy, 105(1), 1-29.

Aminud, Y., And B. Lev (1981): "Risk Reduction as a Managerial Motive for Conglomerate Mergers," Bell Journal of Economics, 12(2), 605-617.

Baker, G., And B. Jorgensen (2003): "Volatility, Noise, and Incentives," mimeo, Harvard University.

Bester, H. (2003): "Externalities and the Allocation of Decision Rights in the Theory of the Firm," CEPR Discussion Paper No. 3276.

\footnotetext{
mimeo, FU Berlin.

Bester, H., and D. KrÄhmer (2006): "Delegation and Incentives," SFB/TR 15 Discussion Paper No. 190.
} 
Burkart, M., D. Gromb, and F. Panunzi (1997): "Large Shareholders, Monitoring, and the Value of the Firm," Quarterly Journal of Economics, 112(3), 693-728.

Core, J., And J. Qian (2002): "Project Selection, Production, Uncertainty, and Incentives," mimeo, University of Pennsylvania.

DeMarzo, P., And D. Duffie (1995): "Corporate Incentives for Hedging and Hedge Accounting," Review of Financial Studies, 8(3), 743-771.

Demski, J., And R. Dye (1999): "Risk, Return, and Moral Hazard," Journal of Accounting Research, 37(1), 27-55.

Dewatripont, M., And J. Tirole (1994): "A Theory of Debt and Equity: Diversity of Securities and Manager-Shareholder Congruence," Quarterly Journal of Economics, 109(4), 1027-1054.

Dutta, S., And S. Reichelstein (2002): "Controlling Investment Decisions: Depreciation and Capital Charges," Review of Accounting Studies, 7, 253-281.

Fershtman, C., And K. Judd (1987): "Equilibrium Incentives in Oligopoly," American Economic Review, 77, 927-940.

Guo, M., And H. Ou-Yang (2006): "Incentives and Performance in the Presence of Wealth Effects and Endogenous Risk," Journal of Economic Theory, 129, 150-191.

Hart, O., and J. Moore (2005): "On the Design of Hierarchies: Coordination Versus Specialization," Journal of Political Economy, 113(4), 675-702.

Hirshleifer, D., And Y. Suh (1992): "Risk, Managerial Effort, and Project Choice," Journal of Financial Intermediation, 2, 308-345.

Laffont, J.-J., And D. Martimort (2002): The Theoy of Incentives: The Principal Agent Problem. Princeton Univeristy Press, Princeton.

Lafontaine, F. (1992): "Agency Theory and Franchising: Some Empirical Results," Rand Journal of Economics, 23, 263-283.

Lafontaine, F., and S. Bhattacharyya (1995): "The Role of Risk in Franchising," Journal of Corporate Finance, 2, 39-74.

Lafontaine, F., and K. Shaw (1999): "The Dynamics of Franchise Contracting: Evidence from Panel Data," Journal of Political Economy, 107(5), 1041-1080.

Legros, P., and A. Newman (2004): "Competing for Ownership," mimeo, Boston University.

Lewellen, K. (2006): "Financing Decisions When Managers are Risk Averse," Journal of Financial Economics, 82, 551-589.

May, D. (1995): "Do Managerial Motives Influence Firm Risk Reduction Strategies," Journal of Finance, L(4), 1291-1308. 
Melumad, N., and D. Mookherjee (1989): "Delegation as Commitment: The Case of Income Tax Audits," Rand Journal of Economics, 20, 139-163.

Milgrom, P., And J. Roberts (1992): Economics, Organization and Management. Prentice Hall, Englewood Cliffs, N.J.

MookherJee, D. (2006): "Decentralization, Hierarchies, and Incentives: A Mechanism Design Perspective," Journal of Economic Literature, 44(2), 367-390.

NaGAR, V. (2002): "Delegation and Incentive Compensation," Accounting Review, 77(2), 379-395.

Poitevin, M. (2000): "Can the Theory of Incentives Explain Decentralization?," Canadian Journal of Economics, 33(4), 878-906.

Prendergast, C. (2002): "The Tenous Tradeoff Between Risk and Incentives," Journal of Political Economy, 110, 1035-1070.

Puschke, K. (2007): "The Allocation of Authority in a Joint Project under Limited Liability," Journal of Institutional and Theoretical Economics, forthcoming.

Raith, M. (2003): "Competition, Risk and Manegerial Incentives," American Economic Review, 93, 1425-1436.

Rajan, R., And J. Wulf (2006): "The Flattening Firm: Evidence From Panel Data on the Changing Nature of Corporate Hierarchies," Review of Economics and Statistics, 88(4), 759-773.

Roberts, J. (2004): The Modern Firm. Oxford University Press, Oxford.

Rogoff, K. (1985): "The Optimal Degree of Commitment to an Intermediate Monetary Target," Quarterly Journal of Economics, 100, 1169-1189.

Sappington, D. (1986): "Commitment to Regulatory Bureaucracy," Information Economics and Policy, 2, 243-258.

Smith, C., and R. Stulz (1985): “The Determinants of Firms' Hedging Policies," Journal of Financial and Quantitative Analysis, 20, 391-405.

Sung, J. (1995): "Linearity with Project Selection and Controllable Diffusion Rate in Continuous-Time Principal-Agent Problems," Rand Journal of Economics, 26(4), 720743.

Vickers, J. (1985): "Delegation and the Theory of the Firm," Economic Journal, 95, $138-147$. 